\title{
CISTO DE MESENTÉRIO
}

\author{
MESENTERIC CYST
}

\section{Edson Yuzur Yasojima, TCBC-PA ${ }^{1}$ \\ Meliza Maria Moutinho Cruz ${ }^{2}$ \\ Tárik Olívar de Nunes Valente ${ }^{2}$}

\section{INTRODUÇÃO}

Cistos de mesentério são incomuns e raramente sintomáticos. O diagnóstico costuma ser feito pelo achado de massa abdominal ou durante investigação de outras doenças. Os autores apresentam um caso de cisto mesentérico identificado durante investigação de febre em criança de dez anos.

\section{RELATO DO CASO}

Criança de dez anos, sexo masculino, faioderma, procedente de Belém-Pará, atendida em 3 de julho de 2000 no Hospital da Beneficência Nipo Brasileira da Amazônia, apresentando, como única sintomatologia, quadro febril, com temperatura variando entre $38,5^{\circ} \mathrm{C}$ e $39,5^{\circ} \mathrm{C}$, que cedeu com o uso de antitérmicos. Ao exame físico e exames laboratoriais de rotina não se identificaram alterações. A ultra-sonografia e o CT abdominal revelaram massa de densidade mista, septada, ocupando a cavidade abdominal e pélvica, e indicando como conduta terapêutica a laparotomia para ressecção do cisto.

$\mathrm{Na}$ cirurgia identificou-se cisto de mesentério com cerca de $30 \mathrm{~cm}$ de diâmetro, pesando $4,2 \mathrm{~kg}$ e comprometendo alças de intestino delgado (Figura 1). Procedeu-se à cistectomia com ressecção de segmento de intestino delgado e anastomose término-terminal. O paciente apresentou boa recuperação, sem complicações no pós-operatório, e recebeu alta hospitalar no terceiro dia de pósoperatório.

A peça cirúrgica foi encaminhada para exame histopatológico (Figura 2). À macroscopia o material era representado por segmento de intestino delgado mostrando

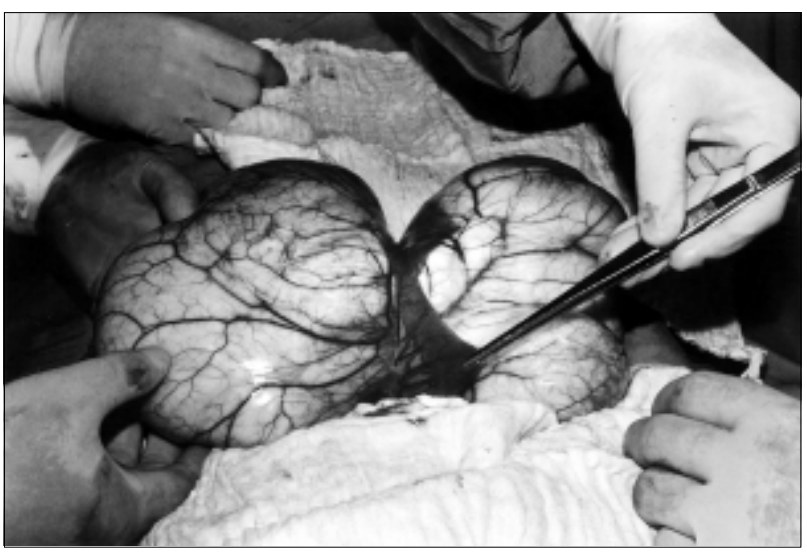

Figura 1 - Cisto Mesentérico comprometendo alça intestinal.

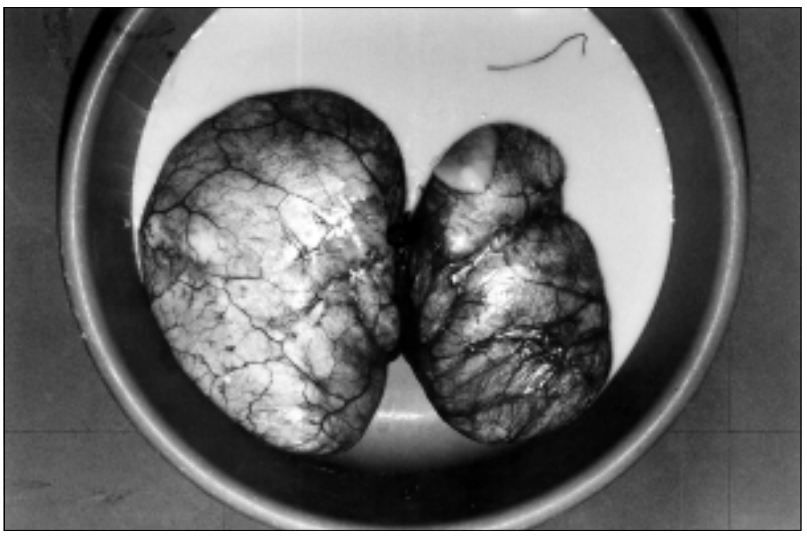

Figura 2 - Peça cirúrgica - Cisto de mesentério.

1. Professor Colaborador do Departamento de Medicina Integrada I — UEPA. Cirurgião do Aparelho Digestivo do Hospital da Beneficência Nipo-Brasileira da Amazônia.

2. Graduando do Curso de Medicina da Universidade do Estado do Pará — UEPA.

Recebido em 12/02/2001

Aceito para publicação em 31/07/2001

Trabalho realizado no Serviço de Cirurgia Geral do Hospital da Beneficência Nipo

Brasileira da Amazônia - Belém-PA. 
ao nível de mesentério formação tumoral cística, de paredes delgadas e enrugadas, deixando ver por transparência vasos sangüíneos dilatados e tortuosos e preenchimento por material leitoso, bastante viscoso. Ao exame microscópico definiu-se fragmento de intestino delgado mostrando, ao nível de mesentério, formação cística revestida internamente por células planas, apoiadas em estroma fibrogorduroso, com intensa congestão vascular e focos discretos de hemorragia e edema. Não havendo sinais de malignidade, concluiu-se como cisto mesentério simples.

\section{DISCUSSÃO}

Cisto de mesentério é uma doença abdominal bastante rara, e, assim como tumores de omento e retroperitônio, pode ser originado de tecido linfático, vascular, nervoso e conjuntivo ${ }^{1}$. Foi sugerido que tais cistos sejam classificados como provenientes dos canais linfáticos, de divertículos entéricos, da crista urogenital ou seus derivados, de infecções circunscritas ou de origem maligna ${ }^{2-4}$. Variam de pequenos nódulos até massas císticas que preenchem a cavidade abdominal como um todo; podem ser únicos ou múltiplos e seu sítio preferencial é o mesentério do intestino delgado. O tipo histológico mais comum é o cisto quiloso ou linfático ${ }^{1,2}$. Sua incidência é discretamente maior em mulheres e a sua freqüência em torno de 1: 100.000 - 1: 250.000 adultos internados e 1: 200.000 crianças internadas ${ }^{1,2}$.

As manifestações clínicas dos cistos mesentéricos são discretas. O diagnóstico muitas vezes é feito na investigação de outras doenças. Neste caso, foi realizado através de ultra-sonografia e tomografia computadorizada abdominal, em investigação de febre.

Exames de laboratório pouco ajudam no diagnóstico. Radiografias simples de abdome podem evidenciar calcificações; arteriografia e trânsito intestinal podem mostrar massa compressiva. Entretanto, a ultra-sonografia, a tomografia computadorizada e a ressonância magnética são os exames que proporcionam melhor acuidade diagnóstica ${ }^{1,5}$.

As intervenções cirúrgicas fazem-se necessárias e vão desde a cistectomia simples até grandes ressecções associadas de mesentério e intestino ${ }^{1}$. A recidiva é rara, mas tem sido relatada frente a outros procedimentos cirúrgicos $^{3-5}$.

O caso reportado classifica-se como um caso raro, não só pela magnitude da patologia, mas por tratar-se de paciente com sintomatologia não relacionada ao tumor.

\begin{abstract}
Mesenteric cyst is a rare abdominal disease, with a higher incidence among women and 1: 250.000 incidence among hospitalized adults and 1: 200.000 among hospitalized children. Thereby, we report a case of a 10 years old child, male, presenting a large mesenteric cyst, which occupied almost all the abdominal and pelvic cavities and treated by resection during laparotomy.
\end{abstract}

Key Words: Cystectomy; Mesenteric cist; Mesentery.

\title{
REFERÊNCIAS
}

1. Miranda EG, Sousa CT. Cisto de mesentério: relato de caso. J. Bras. Med, 1994, 67(5/6):162-4.

2. Yasoshima T, Mukaiya M, Hirata K et al. A chylous cyst of the mesentery: report of a case. Surg. Today, 2000, 30(2):185-7.

3. Bury TF, Pricolo VE. Malignant transformation of benign mesenteric cyst. Am. J. Gastroenterol, 1994, 89(11): 2085-7.

4. Fujita N, Noda Y, Kobayashi G et al. Chylous cyst of the mesentery: US and CT diagnosis. Abdom. Imaging, 1995, 20(3):259-61.
5. Gissler HM, Ross N, Peters PE. Erscheinungsformen der mesenterialzyste. Ein kasuistischer beitrag. Radiologe, 1996, 36(6):503-7

Endereço para correspondência:

Edson Yuzur Yasojima

Tv. 9 de janeiro, 1267 - São Braz

66060-370 - Belém-PA

e-mail: yasojima@terra.com.br 